\title{
Undergraduates Attitudes towards Adopting a Flipped Learning Approach in Jordanian Universities: Empirical Study
}

\author{
Dr. Osamah Abdel Qader Bani Milhem ${ }^{1} \&$ Tamara Adnan Smadi² \\ ${ }^{1}$ Department of Teaching and Curriculum, Faculty of Educational Sciences, The Hashemite University, Jordan \\ ${ }^{2}$ The Ministry of Education, Jordan \\ Correspondence: Dr. Osamah Abdel Qader Bani Milhem, Department of Teaching and Curriculum, Faculty of \\ Educational Sciences, The Hashemite University, P.O. Box 330127, Zarqa 13133, Jordan.
}

Received: December 5, 2020

Accepted: January 15, 2021

Online Published: January 21, 2021

doi:10.5430/ijhe.v10n3p202

URL: https://doi.org/10.5430/ijhe.v10n3p202

\begin{abstract}
The present study investigated the undergraduates' attitudes towards adopting a flipped learning approach in Jordanian universities. An analytical descriptive approach was adopted. The purposive sampling technique was used to choose a sample. This sample consists from 392 BA students. The researchers selected those students from the faculty of education at the University of Jordan. The forms of the questionnaire were distributed by hand. They were retrieved, but 4 ones have been excluded. The final sample consists from 388 BA students. The researchers concluded that the students show positive attitudes towards adopting this learning approach. They found that the flipped learning approach enables students to learn at their own pace and motivates them to learn. It was found that the flipped learning approach facilitates the process of taking notes and improves the students' comprehension of information. The researchers recommend enacting policies for encouraging faculty members at Jordanian universities to adopt a flipped instructional approach. They recommend using social media by faculty members at Jordanian universities when adopting a flipped instructional approach. That shall motivate students to learn.
\end{abstract}

Keywords: undergraduates, attitudes, flipped learning approach, Jordanian universities

\section{Introduction}

Technology has been playing a very significant role in reforming the educational process (Adam and Nel, 2009). Technology has been highly employed by instructors and learners at home and educational institutions. Despite that, the valuable important role of the conventional classroom can't be overlooked. The conventional classroom refers to the classroom that includes students who are attending physically (i.e. the teacher meets the learners face to face). In this classroom, the instructor shall have face-to-face interaction with his/her students (Raths, 2014).

In the light of having rapid technological developments, the flipped learning approach has emerged. The latter approach represents a reverse for the conventional learning approach. In other words, it aims to switch the mechanism used when adopting a conventional learning approach. To illustrate more, through the conventional learning approach, students usually listen to the instructor inside the classroom. After that, students shall go home to do their homework, read the course material, and assimilate the material through watching academic videos uploaded to the web. However, through the flipped learning approach, students shall be introduced to the course material at home through using an electronic mean (e.g. watching videos of pre-recorded lessons that are uploaded to the web). After that, they shall attend classes in order to apply and discuss the things they have learnt earlier at home (Gilboy et al., 2015; Betihavas et al., 2015).

The flipped learning approach allows students to be well-prepared before coming to the class. It increases the students' interaction and participation in classroom. It provides students with more time to hold discussions in classroom and exchange ideas (Bergmann and Sams, 2014). It serves as a very flexible learning approach. It shall enable teachers and students to save their valuable time. That is because the time spent in classroom shall be dedicated for holding discussions rather than giving direct instruction. It shall increase the quality of the provided education. That's because the lessons have been already prepared by students before coming to class (Milman, 2012).

The flipped learning approach shall enable students and teachers to cover the whole material of the curriculum during the semester which may be difficult in some cases. It shall increase students' self-confidence in the classroom 
and motivate them to learn. It shall increase students' engagement in the teaching-learning process. That is because the pupils have prepared the lesson at home and gained knowledge about the lesson material and content before coming to class (Hamdan et al., 2013)

Regarding the flipped learning approach, it permits pupils to learn in manner that fits with their learning pace. It can significantly encourage the pupils to engage in an active manner in the discussions held at classroom about the course material. It provides students in class with more time to learn. It promotes creativity among students. It turns students into active learners (Gilboy et al., 2015; Betihavas et al., 2015). After reviewing the works related to this approach, the researchers aimed to investigate the undergraduates' attitudes towards adopting a flipped learning approach in Jordanian universities.

\section{The Study's Objective}

This study investigated the undergraduates' attitudes towards adopting a flipped learning approach in Jordanian universities.

\section{The Study's Question}

What are the undergraduates' attitudes towards adopting a flipped learning approach in Jordanian universities?

\section{The Study's Limits}

The study's limits are:

Human limits: This study targets the undergraduates who are enrolled at Jordanian universities.

Spatial limits: The researchers conducted the study in the University of Jordan

Temporal limits: Data was collected in this study during the first semester of the academic year 2019/2020.

Thematic limits: The researchers target the attitudes of the undergraduates towards adopting a flipped learning approach in Jordanian universities.

\section{The Study's Significance}

This research is deemed important. That's attributed to the lack of the studies that shed a light on this approach in the universities in Jordan. This research is deemed important because it offers results and information that are significant and useful for

The Jordanian Ministry of Higher Education and Scientific Research: The present study shall provide the latter ministry with information about undergraduates' skills in using ICT. Such information shall enable the latter ministry to develop effective policies and plans for developing the ICT skills of undergraduates.

Researchers: This study offers information to the researchers who are interested in carrying out similar research. It offers those researchers an instrument that is reliable. This instrument was developed based on the relevant literature.

Faculty members at Jordanian universities: This study provides those faculty members with reliable information about the undergraduates' attitudes towards flipped learning. Such information can be utilized by those faculty members for raising the quality level of the teaching-learning process.

\section{Definition of Terms}

\subsection{Operational Definitions}

-Flipped learning: It refers to uploading videos and course materials to the web in order for students at Jordanian universities to read such materials and watch such videos before attending the lecture.

-Attitudes: They refer to the undergraduates' attitudes towards adopting a flipped learning approach in Jordanian universities.

\subsection{Theoretical Definitions}

-Attitudes: They refer to evaluative judgments that represent the extent of preferring something or someone (Crano and Prislin, 2006, p.347).

-Flipped learning: Through this approach, students shall be introduced to the course material at home through using an electronic mean. After that, they shall attend classes in order to apply and discuss the things they have learnt earlier at home (Gilboy et al., 2015; Betihavas et al., 2015).

\section{Theoretical literature}

Fulton (2012) suggest that there are several advantages for adopting a flipped learning approach. For instance, this 
approach offers students the opportunity to learn in a manner that fits with their learning pace. It enables teachers to identify the difficulties that students face when doing homework. It enables teachers to upload and upgrade the learning material. It enables teachers to upgrade the material in accordance with the students' learning needs. It makes students in classroom more active and raises the effectiveness of the teaching-learning process in classroom. It enables teachers to identify the students' interests (Fulton, 2012).

Flipped learning promotes autonomy among learners. In other words, it enables students to rely on themselves for obtaining knowledge and acquiring skills. It changes the teachers' responsibilities. For instance, it makes teachers responsible for motivating students to learn. It makes teachers responsible for facilitating knowledge rather than delivering information in a direct manner through the spoon-feeding method (Driscoll and Petty, 2013).

The flipped learning approach has numerous advantages. That is because it combines several learning approaches. These approaches are: the project and problem-based approaches. They also include: the collaborative and active approaches. Thus, the flipped approach improves students' problem solving skills and promotes collaboration among students (Prince, 2014). It changes the role of students in the teaching-learning process. For instance, it turns students from passive learners into active learners. It provides students with education of high quality. It enables learners to learn at their pace, and reduces their frustration levels (Du et al., 2014).

The flipped approach enables the students who have a special personality type-e.g. shy students - to engage in the process of teaching-learning in an active manner. It promotes social interaction among students. It promotes acceptance among students for the existence of cultural diversity in society in general and classroom in particular. It enables teachers to work closely with students in classroom. It improves the teamwork skills of students (Du et al., 2014)

However, several challenges are associated with adopting a flipped approach. For instance, some students don't have an internet access at home. There are students who live in remote areas and don't have internet coverage. In addition, some students don't have their own personal computers. Hence, some students may be forced to use computers at public facilities, such as: public libraries. In addition, some students may not be motivated to adopt this learning approach. Some student show resistance to the process of adopting this approach. That shall negatively affect the effectiveness of this learning approach. In addition, when adopting this approach, there shall be challenges faced when assessing students (Du et al., 2014).

Herreid et al. (2014) suggests that this approach allows students to utilize the class time efficiently. According to Nederveld and Berge (2015), the flipped learning approach offers training opportunities for developing skills. It offers training opportunities for developing the ability to use a software. It offers learners ongoing support and facilitates the learners' communication and cooperation with each other. It allows learners to share resources with each other. Such resources include: journal articles, books and etc.. This approach allows students to upload videos, and audio files. It allows students to explore and understand the meaning of concepts. It offers opportunities for applying knowledge (Nederveld and Berge, 2015).

According to Zainuddin \& Halili (2015), the flipped learning approach allows students to construct and produce new knowledge based on their prior knowledge. It develop students in cognitive areas. It develops students' self-assessment skills. For instance, it allows students to assess their learning outcomes. It improves students' ability to write a summary, and engage in debates. It improves students' creative thinking and ability to interpret information. It facilitates the process of recalling information. It improves achievement, motivation to learn, and engagement in learning activities. It improves students' interaction with the academic content, instructors and peers (Zainuddin \& Halili, 2015)

O'Flaherty \& Phillips (2015) suggests that this approach makes students responsible for managing their own learning process. According to Iwaniec et al. (2017), the flipped learning approach serves as a student-centred learning approach. It contributes to improving the problem solving skills and analytical skills. It develops students' critical thinking skills. It offers students opportunities to practice and implement core skills related to their major. It improves students' understanding for the material. It allows students to identify the approach to be adopted for solving a problem. It provides students with opportunities to implement strategies for solving problems. It allows students to identify the gaps in their knowledge (Iwaniec et al., 2017).

The flipped learning approach allows students to avoid the mistakes that might be committed by them. It allows students to correct their misunderstanding of things. It contributes to making the learning process enjoyable, attracting and interesting. It improves students' understanding. Thus, it improves students' confidence in their 
knowledge, abilities and skills. It promotes a sense of independency in learning. It is an effective approach for the ones whose don't master the use of the language being used in class (Iwaniec et al., 2017).

According to Lag, and Sæle (2019), the flipped learning approach increases students' satisfaction with their learning outcomes and experiences. It also increases students' satisfaction with their assessment process and course quality. It improves the scores on texts. It positively affects students' pass rates in courses (Lag, and Sæle, 2019)

\section{Review of Empirical Studies}

Basal (2015) investigated the perception of forty seven faculty members teaching English language in Turkey towards the flipped classroom. A questionnaire was used for collecting data. The sample was chosen from a public university that is located in Turkey. A qualitative approach was adopted. It was found that those faculty members have positive attitudes towards learning English language in such type of classrooms. It was found that the flipped classroom offers students the opportunity to learn in a manner that fits with their learning pace. Such a classroom makes students well-prepared in advance. This approach raises students the degree to which students are engaged in the teaching-learning process. It enables students to overcome the limitation of class time (Basal, 2015).

Abaeian and Samadi (2016) investigated the impacts of the flipped classroom on the reading comprehension of Iranian EFL learners. They sampled 100 female students. The control group includes 50 female students and the experimental group includes the rest of the students. Pre-test and post-test were used for collecting data. The members of the experimental group are taught in flipped classroom. It was found that the flipped classroom plays a significant role in improving such comprehension regardless of the language proficiency

Karimi and Hamzavi (2017) investigated the effectiveness of adopting a flipped instructional model in raising the reading comprehension level. They aimed to investigate the Iranian EFL learners' attitudes towards adopting the latter approach. They adopted an experimental approach and a descriptive approach. The sample consists from 50 Iranian EFL learners. Questionnaire, and a pre-test were used. The post-test was used. It was found that adopting a flipped model of instruction shall effectively raise EFL leaners' achievement in the reading comprehension. The sampled students prefer learning through the flipped model of instruction rather than the conventional one. The flipped model of instruction increased students' sense of confidence about their capabilities to learn (Karimi and Hamzavi, 2017).

The flipped model of instruction facilitates the process of comprehending texts and improves students' communication skills. It increases students' understanding for information. It improves the way in which the faculty members manage time during the lecture. It can raise the students' degree of engagement in the learning-teaching process in classroom. It provides students with many online resources that expand their knowledge. It increases students' opportunities to communicate with their colleagues. It enables students to submit assignments online and receives online feedback on such assignments (Karimi and Hamzavi, 2017)

Farrah and Qawasmeh (2018) investigated the perception of students at Hebron University towards learning a language in a flipped classroom. They employed a questionnaire. They surveyed 150 students at the latter university. They conducted interviews with 10 students of the surveyed students. Through using the questionnaire, several results were reached. For instance, the respondents show attitudes that are positive. In addition, the flipped classroom made students self-directed learners. It encourages students to ask questions and enables them to get the answers they want to difficult questions. It offers students more opportunities to communicate with their colleagues. It provides students with more time to play and carry out extra-curricular activities. Through conducting the interviews, several results were reached. For instance, the flipped classroom increased students' knowledge. It can significantly enhance students' team work and communication skills (Farrah and Qawasmeh, 2018).

Dusenbury \& Olson (2019) investigated the influence of flipped learning on students' perceptions and academic performance. 81 students were sampled. They are chosen from Midwestern University in the United States. A pre-test along with a post-test were used. Questionnaire was employed for data collection. Several results were reached. For instance, flipped learning raises the satisfaction of students with the learning process. Flipped learning improves students' perceptions towards learning and raises their academic performance. It increases students' engagement in the process of learning. It increases students' comprehension for the illustrated information and stimulates students' thinking to propose new ideas. It eliminates misunderstandings. It facilitates the process of taking notes (Dusenbury \& Olson, 2019).

Nouri (2016) investigated the degree to which the flipped approach is effectively, especially among low achievers. 240 students were surveyed. Those students were selected from Stockholm University. They were selected from the Computer and Systems Sciences Department. $90.40 \%$ of the respondents have a prior experience in learning through 
adopting a flipped learning approach. Several findings were reached. For instance, the flipped learning approach makes students handle the responsibility of their own learning. This approach offers students the opportunity to learn in a manner that fits with their learning pace. It makes the learning process easier. It motivates students to learn. It enables students to learn more information. It turns students into active learners. It promotes peer-collaboration. Respondents have positive attitudes towards adopting the flipped learning approach. Low achievers have more positive attitudes than other students towards adopting this approach (Nouri, 2016).

\section{Methodology}

\subsection{Approach}

A descriptive analytical approach was adopted. It is usually adopted by researchers for providing a description for phenomena and items. It enables one to have a better understanding for information (Lawless and Heymann, 1999). It is adopted for conducting studies in many fields, such as: the fields of psychology, education, and social sciences. It aimed to describe the characteristics of phenomenon. It's concerned with (what) questions rather than how or why questions. It aims at describing what has occurred and its characteristics. The researchers also adopted a quantitative approach. Through this approach, they collected data from the respondents and analyzed it quantitatively through using statistical methods (Nassaji, 2015)

\subsection{Methods for Data Collection}

The researchers collected primary data through using questionnaire forms. They collected secondary data through reviewing the relevant books, studies, and periodicals.

\subsection{Instrument}

The researchers developed a questionnaire based on the relevant theoretical and empirical literature. They adopted the five point Likert scale. They distributed the forms in Arabic language to the respondents. The first part of the questionnaire collects data about the respondents' skills in using ICT, and gender. The second part collects data about the respondents' attitudes towards adopting a flipped learning approach in Jordanian universities. It consists from 12 statement. It was developed based on the works published by: Hamdan et al. (2013), Farrah and Qawasmeh (2018),Karimi \&Hamzavi (2017), Abaeian \& Samadi (2016), Dusenbury \& Olson (2019), Nouri (2016), and Basal (2015).

\subsection{Validity of the Instrument}

For measuring such a validity, the initial form of the questionnaire was passed to 2 faculty members. The selected faculty members are specialized in educational sciences and have been working in Jordanian universities for many years. They were asked to provide an assessment for the questionnaire in terms of language, clarity, content, and relevancy. All the faculty members added that the questionnaire enables the scholars to meet the study's goal. They added that the items are easy to understand and clear. They suggested that it's written in a good manner. However, a faculty member recommended doing changes to the form. Another faculty member recommended correcting a couple of language mistakes. Thus, changes were made and the final version was drafted.

\subsection{Reliability of the Instrument}

In order to measure such reliability, the researchers calculated Cronbach Alpha coefficient. This value is 0.801 . Thus, the instrument is highly reliable and offer accurate results. That's because the value is greater greater than 0.70 as it's suggested by Salehi \& Farhang (2019).

\subsection{Sample and Population}

The researchers selected a purposive sample consisting from 392 students. All the selected students are BA students. They are selected from the faculty of education at the University of Jordan in Amman, Jordan. The forms of the questionnaire are distributed by hand. All the forms were retrieved. Despite that, 4 forms were excluded due to having missing data. Thus, the final sample consists from 388 students. Data is presented below about the sample

Table 1. Data about the respondents

\begin{tabular}{llll}
\hline Question & Category & Frequency & Percentage\% \\
\hline How do you assess your & Excellent & 20 & 5.1 \\
skills in using ICT? & very good & 66 & 17 \\
& Good & 180 & 46.6 \\
\hline
\end{tabular}




\begin{tabular}{llll}
\hline & Fair & 67 & 17.2 \\
\multirow{3}{*}{ Gender } & Poor & 55 & 14.1 \\
& Female & 261 & 67.2 \\
& Male & 127 & 32.7 \\
\hline
\end{tabular}

$\mathrm{N}=388$

Based on the aforementioned data, $67.2 \%$ of the respondents are females, whereas $32.7 \%$ of the respondents are males. $46.6 \%$ of the selected students show good skills in the use of ICT. $17.2 \%$ of the respondents show air skills in the use of ICT. $14.1 \%$ of the selected students show poor skills in the use of ICT. These percentages indicate that the Jordanian universities must provide students with more training about the use of ICT. Such training courses shall enable students in Jordanian universities to keep up with the latest developments in the field of ICT. They shall enable students to acquire knowledge through using electronic sources.

\subsection{Statistical Analysis and Criteria}

To have the collected data analyzed, the researchers used the SPSS program. They used descriptive statistical methods for analyzing data. Such methods include: standard deviations, percentage and frequencies, and means. They are also considered quantitative statistical methods too. They also identified the level of each mean. For having means classified, the criteria below are adopted.

Table 2. The criteria adopted for having the means classified

\begin{tabular}{lll}
\hline Range & Level & Attitude \\
\hline 2.33 or less & Low & Negative \\
$2.34-3.66$ & Moderate & Neutral \\
3.67 or more & High & Positive \\
\hline
\end{tabular}

Table 3 presents information about the five point Likert scale

Table 3. The categories and scores of the five point Likert scale

\begin{tabular}{llllll}
\hline Category & Strongly agree & Agree & Neutral & Disagree & Strongly disagree \\
\hline The score it represents & 5 & 4 & 3 & 2 & 1
\end{tabular}

\section{Discussion and Results}

What are the undergraduates' attitudes towards adopting a flipped learning approach in Jordanian universities?

Table 4. The undergraduates' attitudes towards adopting a flipped learning approach in Jordanian universities

\begin{tabular}{|c|c|c|c|c|c|}
\hline No. & Statement & Mean & Std. & Attitude & Level \\
\hline \multicolumn{6}{|c|}{ Adopting a flipped learning approach: } \\
\hline 1. & improves the way faculty members manage time during lecture & 2.31 & 0.73 & Negative & Low \\
\hline 2. & $\begin{array}{l}\text { offers students the ability to learn in a manner that fits with } \\
\text { their learning pace }\end{array}$ & 4.96 & 0.21 & Positive & High \\
\hline 3. & motivates students to learn & 4.78 & 0.15 & Positive & High \\
\hline 4. & facilitates the note taking process & 4.85 & 0.64 & Positive & High \\
\hline 5. & increases students' comprehension for information & 4.71 & 0.96 & Positive & High \\
\hline 6. & increases students' satisfaction with the learning process & 4.43 & 0.73 & Positive & High \\
\hline 7. & $\begin{array}{l}\text { raises students' extent of engagement in the teaching-learning } \\
\text { process inside the classroom. }\end{array}$ & 4.64 & 0.28 & Positive & High \\
\hline 8. & increases students' reading comprehension & 4.76 & 0.44 & Positive & High \\
\hline 9. & increases students' language proficiency level. & 4.81 & 0.21 & Positive & High \\
\hline 10. & improves students' communication skills & 2.19 & 0.57 & Negative & Low \\
\hline 11. & increases students' knowledge & 4.65 & 0.31 & Positive & High \\
\hline
\end{tabular}


12 enables faculty members to cover the whole material during

2.24

0.46

Negative

Low the semester

Total

4.11

0.47

Positive

High

Based on table (4), it was found that the undergraduates' attitudes towards adopting a flipped learning approach in Jordanian universities are positive due to having an overall mean of 4.11. Such attitudes are consistent with the result reached by Farrah and Qawasmeh (2018). They can be attributed to the fact that learners enjoy the use of technology. It was found that adopting a flipped learning approach doesn't improve the way faculty members manage time during lecture due to having a mean of 2.31. The result in this regard is inconsistent with the result that has been reached by Karimi and Hamzavi (2017). That is because the faculty member's capability to manage time effectively during lecture is affected by the training he/she has received.

Adopting a flipped learning approach offers students the ability to learn in a manner that fits with their learning pace due to having a mean of 4.96. The result in this regard is consistent with the result reached by Basal (2015). That is because students can watch the video as much as they want. It is because students can fast-forward the video whenever they want. In addition, adopting a flipped learning approach motivates students to learn due to having a mean of 4.78. That may be because using multimedia and technology motivates students to learn. The latter result is consistent with the result reached by Nouri (2016).

Adopting a flipped learning approach facilitates the note taking process, due to having a mean of 4.85. The result in this regard is consistent with the result concluded by Dusenbury \& Olson (2019). That's because colleagues can share summaries for the course material with each other through the web. Such summaries shall facilitate the note taking process. The researchers concluded that adopting a flipped learning approach increases students' comprehension for information, due to having a mean of 4.71. The result in this regard is consistent with the result concluded by Dusenbury \& Olson (2019). That's because students will come to class in order to apply and discuss the things they have learnt at home. That's because students in class will be given the opportunity to ask questions about the difficult things they couldn't understand at home by themselves.

The researchers concluded that adopting a flipped learning approach increases students' satisfaction with the learning process, due to having a mean of 4.43 . The result in this regard is consistent with the result concluded by Dusenbury \& Olson (2019). That's because faculty members can customize the teaching-learning process in a manner that meets the learning needs of each student.

The researchers concluded that the flipped learning approach raises students' extent of engagement in the teaching-learning process inside the classroom, due to having a mean of 4.64. The result in this regard is consistent with the result concluded by Karimi and Hamzavi (2017). That's because adopting this approach shall allow students to attend class with being well-prepared. That shall make students more capable to engage in the learning activities and discussions that are held at class.

The researchers concluded that the flipped learning approach increases students' reading comprehension, due to having a mean of 4.76. The result in this regard is consistent with the result concluded by Abaeian and Samadi (2016). That's because students shall be provided with many online resources about reading strategies. The researchers concluded that the flipped learning approach increases students' language proficiency, due to having a mean of 4.81. The result in this regard is consistent with the result concluded by Abaeian and Samadi (2016). It may be attributed to the fact that students shall be provided with several opportunities to interact with native speakers online and practice the language with their peers outside the classroom.

The researchers concluded that a flipped learning approach doesn't improve students' communication skills, due to having a mean of 2.19. The result in this regard is inconsistent with the result concluded by Karimi and Hamzavi (2017) and Farrah and Qawasmeh (2018). That's because adopting a flipped learning approach shall reduce the extent of having face-to-face interaction with peers and faculty members.

The researchers concluded that the flipped learning approach increases students' knowledge, due to having a mean of 4.65. The latter result is consistent with the result concluded by Farrah and Qawasmeh (2018). That's because adopting a flipped learning approach shall provide students with many information sources. Such sources shall expand their knowledge and make them informative. The researchers concluded that adopting a flipped learning approach doesn't enable faculty members to cover the whole material during the semester, due to having a mean of 2.24. The result in this regard is inconsistent with the result concluded by Hamdan et al. (2013). It may be attributed to the fact that covering the whole material is affected by the time management skills of the faculty member giving 
the course. Some faculty members have poor time management skills which hinders them from covering the whole material.

\section{Conclusion}

Through analyzing the collected data, several results were reached. For instance, it was found that undergraduates' attitudes towards adopting a flipped learning approach in Jordanian universities are positive. In addition, adopting a flipped learning approach enables students to learn at their own pace. It motivates students to learn. It facilitates the process of taking notes and increases students 'comprehension for information. It increases students' satisfaction with the learning process and raises students' extent of engagement in the teaching-learning process inside the classroom. It increases students' reading comprehension and language proficiency levels. It expands students' knowledge. However, it doesn't improve the way faculty members manage time during lecture. It doesn't improve students' communication skills.

\section{Recommendations}

The researchers recommend

1- Encouraging faculty members at Jordanian public and private universities to adopt a flipped instructional approach.

2- Holding training courses for faculty members at Jordanian universities about the advantages of adopting a flipped instructional approach.

3- Enacting policies for encouraging faculty members at Jordanian universities to adopt a flipped instructional approach.

4- Using social media by faculty members at Jordanian universities when adopting a flipped instructional approach. That shall motivate students to learn.

5- Conducting other studies about students' attitudes towards other learning approaches in Jordanian universities. That shall improve the quality of higher education in Jordan.

\section{Acknowledgement}

The researchers thank faculty members and academic leaders in Jordanian universities for exerting effort to improve education.

\section{References}

Abaeian, H., \& Samadi, L. (2016). The effect of flipped classroom on Iranian EFL learners' L2 reading comprehension: Focusing on different proficiency levels. Journal of Applied Linguistics and Language Research, 3(6), 295-304.

Adam, S., \& Nel, D. (2009). Blended and online learning: Student perceptions and performance. Interactive technology and smart education, 6(3), 140-155. https://doi.org/10.1108/17415650911005366

Basal, A. (2015). The implementation of a flipped classroom in foreign language teaching. Turkish Online Journal of Distance Education, 16(4), 28-37. https://doi.org/10.17718/tojde.72185

Bergmann, J., \& Sams, A. (2014). Flipped learning: Maximizing face time. Training \& Development, 68(2), $28-31$.

Betihavas, V., Bridgman, H., Kornhaber, R., \& Cross, M. (2015). The evidence for 'flipping out': A systematic review of the flipped classroom in nursing education. Nurse Education Today, 6, 15-21. https://doi.org/10.1016/j.nedt.2015.12.010

Crano, W. D., \& Prislin, R. (2006). Attitudes and persuasion. Annual Review of Psychology, Vol. 57, $345-374$. https://doi.org/10.1146/annurev.psych.57.102904.190034

Driscoll, T. F., \& Petty, K. A. (2014). Student-driven education with flipped learning and 20-time. In L. Kyei-Blankson, \& E. Ntuli (Eds.), Practical Applications and Experiences in K-20 Blended Learning Environments (pp. 120-136). Hershey, PA: IGI Global. https://doi.org/10.4018/978-1-4666-4912-5.ch009

Du, S.; Fu, Z., \& Wang, Y. (2014). The flipped classroom-advantages and challenges. International Conference on Economic Management and Trade Cooperation (EMTC 2014). This conference was held on $12^{\text {th }}-13^{\text {th }}$, April, 2014 in China.

Dusenbury, M. J., \& Olson, M. R. (2019). The impact of flipped learning on student academic performance and perceptions. Collegiate Aviation Review International, 37(1), 19-44. https://doi.org/10.22488/okstate.19.100202 
Evans, J. R., \& Mathur, A. (2005). The value of online surveys. Internet Research, 15(2), 195-219. https://doi.org/10.1108/10662240510590360

Farrah, M., \& Qawasmeh, A. (2018). English students' attitudes towards using flipped classrooms in language learning at Hebron University. Research in English Language Pedagogy, 6(2): 275-294. https://doi.org/10.30486/RELP.2018.542708

$\mathrm{Fu}$, J. S. (2013). ICT in education: A critical literature review and its implications. International Journal of Education \& Development using Information \& Communications Technology, 9(1), 112-125.

Fulton, K. (2012). Upside down and inside out: Flip your classroom to improve student learning. Learning \& Leading with Technology, 39(8), 12-17.

Gilboy, M. B., Heinerichs, S., \& Pazzaglia, G. (2015). Enhancing student engagement using the flipped classroom. Journal of nutrition education and behavior, 47(1), 109-114, https://doi.org/10.1016/j.jneb.2014.08.008

Hamdan, N., McKnight, P., McKnight, K., \& Arfstrom, K. M. (2013). The flipped learning model: A white paper based on the literature review titled A Review of Flipped Learning'. Arlington, VA: Flipped Learning Network

Herreid, C. F., Schiller, N. A., Herreid, K. F., \& Wright, C. B. (2014). A chat with the survey monkey: Case studies and the flipped classroom. Journal of College Science Teaching, 44, 75-8. https://doi.org/10.2505/4/jcst14_044_01_75

Iwaniec, M., Simmonds, T., \& Swan, Z. (2017). A practical case study exploring how flipped learning affects the development of problem solving skills in two different disciplines. Compass: Journal of Learning and Teaching, 10(1). https://doi.org/10.21100/compass.v10i1.426

Karimi, M., \& Hamzavi, R. (2017). The effect of flipped model of instruction on EFL learners' reading comprehension: learners' attitudes in focus. Advances in Language and Literary Studies, 8(1). 95-103. https://doi.org/10.7575/aiac.alls.v.8n.1p.95

Lag, T., \& Sæle, R. (2019). Does the Flipped Classroom Improve Student Learning and Satisfaction? A Systematic Review and Meta-Analysis. AERA Open, 5(3), 1-17. https://doi.org/10.1177/2332858419870489

Lawless H. T., \& Heymann H. (1999) Descriptive analysis. In: Sensory evaluation of food. Food science text series. Springer, Boston, MA. https://doi.org/10.1007/978-1-4419-7452-5

Milman, N. B. (2012). The flipped classroom strategy: What is it and how can it best be used? Distance Learning, $9(3), 85-87$.

Nassaji, H. (2015). Qualitative and descriptive research: Data type versus data analysis. Language Teaching Research, 19(2). https://doi.org/10.1177/1362168815572747

Nederveld, A., \& Berge, Z. (2015). Flipped learning in the workplace. Journal of Workplace Learning, 27(2), 162-172. https://doi.org/10.1108/JWL-06-2014-0044

O'Flaherty, J., \& Phillips, C. (2015). The use of flipped classrooms in higher education: A scoping review. The Internet and Higher Education, 25, 85-95. https://doi.org/10.1016/j.iheduc.2015.02.002

Prince, M. (2004). Does active learning work a review of the research, Journal of Engineering Education, 93(3), 223-231. https://doi.org/10.1002/j.2168-9830.2004.tb00809.x

Salehi, M., \& Farhang, A. (2019). On the adequacy of the experimental approach to construct validation: the case of advertising literacy. Heliyon, 5(5). Retrieved from: https://doi.org/10.1016/j.heliyon.2019.e01686

Zainuddin, Z., \& Halili, S. H. (2016). Flipped Classroom Research and Trends from Different Fields of Study. The International Review of Research in Open and Distributed Learning, 17(3). https://doi.org/10.19173/irrodl.v17i3.2274

\section{Copyrights}

Copyright for this article is retained by the author(s), with first publication rights granted to the journal.

This is an open-access article distributed under the terms and conditions of the Creative Commons Attribution license (http://creativecommons.org/licenses/by/4.0/). 